\title{
Posicionamentos e orientações institucionais: uma nota de cautela*
}

\author{
Claudio Gil Soares de Araújo ${ }^{1}$ \\ Programa de Pós-Graduação - Educação Física - UGF, Serviço de Medicina do Exercício \\ e do Esporte - HUCFF/UFRJ e Departamento de Fisiologia - UFF, Rio de Janeiro, Brasil
}

\begin{abstract}
Organizações científicas respeitadas são melhor reconhecidas através do nível acadêmico de seus membros e pelo impacto científico e tradição de suas publicações periódicas e de seus congressos. Nas últimas duas décadas e, mais especificamente, nos últimos anos, a produção de documentos institucionais pelas organizações científicas tem-se tornado bastante freqüente. Mais apropriadamente chamados de documentos institucionais, esses artigos recebem diferentes denominações, tais como posicionamentos, orientações ou consensos. Tipicamente, especialistas ou pesquisadores ilustres em certa área ou subárea do conhecimento são convidados para utilizar sua experiência técnico-científica na preparação dos documentos, os quais são, muitas vezes, posteriormente revisados por outros especialistas internos e/ou externos à instituição. Em determinados casos, ainda há o endosso do documento final por uma comissão ou da diretoria da referida instituição. Em determinados casos, outras organizações científicas afins também podem associar-se e subscrever e endossar o documento final. Considerando esses aspectos, documentos institucionais passam a merecer elevada prioridade em termos de aceitabilidade e respeitabilidade acadêmica, desde que eles presumivelmente refletem o estado-da-arte em um dado tópico e teriam sido, obrigatoriamente, alvo de meticulosa revisão antes da publicação. Em adendo, esses documentos são freqüentemente empregados como referências ou padrões para a implantação de rotinas laboratoriais, para a preparação de algoritmos de decisão clínica e até mesmo para definir critérios e padrões de conduta apropriada, com implicações legais e pro-
\end{abstract}

1. Fellow do Colégio Americano de Medicina Desportiva; Coordenador do Curso de Especialização em Medicina do Exercício e do Esporte Universidade Estácio de Sá/Clinimex; Vice-Presidente de Reabilitação Cardíaca do Departamento de Ergometria e Reabilitação Cardíaca da Sociedade Brasileira de Cardiologia.

Endereço para correspondência:

Clínica de Medicina do Exercício

Rua Siqueira Campos, 93/102

22031-070 - Rio de Janeiro, RJ

Tel. (021) 256-7183

E-mail: cgaraujo@iis.com.br

Rev Bras Med Esporte - Vol. 5, № 4 - J ul/ A go, 1999 fissionais. Em um esforço para manter o nível de estado-daarte, os documentos institucionais mais relevantes são periodicamente revisados e novas versões ou edições publicadas.

Certamente, considerando o fato de que é impossível para qualquer indivíduo ou pequeno grupo de indivíduos lidar com a enorme e crescente quantidade de dados científicos disponíveis, é natural esperar algum viés no processo redacional que reflita as concepções, opiniões e, até mesmo, as intuições dos especialistas envolvidos no processo de preparação do documento. Muitas vezes, quando os documentos são preparados em reuniões com vários especialistas participantes, a capacidade de argumentar no momento correto e de forma apropriada tende a direcionar o formato e o conteúdo final do documento, em detrimento de outras boas idéias, que, todavia, não teriam sido tão bem defendidas. Um leitor experiente e conhecedor profundo da literatura no tópico do documento é freqüentemente capaz de reconhecer, dentre a lista de especialistas autores, o responsável por determinada sentença, tabela ou comentário. Enquanto isso não deve ser considerado uma fraqueza importante, deverá, por outro lado, ser colocado dentro de uma perspectiva apropriada, na qual se inclui não concluir que todos os participantes do documento, ou até mesmo a maioria dos membros dessa organização, aprovam completamente as recomendações expressas no texto final. Desde que consenso completo é muito raro em ciências biológicas e sociais, os leitores devem sempre considerar esta limitação crucial e relevante em qualquer documento institucional.

Enquanto discussões ou argumentações teóricas podem ser tecidas com relação a muitos aspectos desses documentos, é apropriado esperar que grandes erros não deverão ser encontrados. Infelizmente, isso é raramente verdadeiro. Apresentamos, a seguir, exemplos de equívocos e erros importantes em quatro documentos relevantes e recentes do Colégio Americano de Medicina Desportiva.

\section{1) ACSM's Guidelines for Exercise Testing and Prescription $-5^{\text {th }}$ edition}

P. 138: A figura 6-3 apresenta critérios padrões para a identificação de isquemia miocárdica em traçados de eletrocar- 
diograma. No primeiro diagrama, descrevendo como clássico, existe um erro óbvio: o posicionamento das expressões "anormal" e "normal" foi invertido, modificando completamente o significado e a interpretação clínica.

\section{2) AHA/ACSM Joint Statement: Recommendations for Cardiovascular Screening, Staffing, and Emergency Policies at Health/Fitness Facilities (Med Sci Sports Exerc 1998;30:1009-1018)}

P. 1014: A figura 5 apresenta um diagrama muito interessante para classificação das instalações voltadas para a prática de atividade física. Categorias mutuamente exclusivas são propostas de acordo com certos critérios predefinidos, tais como idade, gênero e número de fatores de risco cardiovascular. Todavia, o exame cuidadoso dos critérios de inclusão para as categorias A-2 (sem fatores de risco) e A-3 (dois ou mais fatores de risco) coloca claramente um problema classificatório para um homem de 50 anos de idade com apenas um fator de risco coronariano, desde que ele não poderia ser classificado em nenhuma das categorias propostas. Na realidade, uma inspeção mais detalhada mostra que não há nenhuma razão prática para separar A-2 e A-3, já que os indivíduos classificados em ambas as categorias poderiam fazer uso do mesmo tipo de instalações para sua prática regular de exercício. Um modo simples de corrigir o erro seria colocar todos os homens com mais de 45 anos de idade e as mulheres com mais de 55 anos de idade, sem doença cardiovascular conhecida, em uma única categoria, talvez denominada A-2 e A-3, para permitir a consistência com documentos anteriores, independentemente do número de fatores de risco.

\section{3) ACSM Position Stand: Exercise and Physical Activity for Older Adults (Med Sci Sports Exerc 1998;30:992-1008)}

P. 997: A inclusão de uma seção sobre flexibilidade deve ser reputada como um dos avanços significativos do documento. Contudo, existem erros óbvios no texto. Por exemplo, o segundo parágrafo dessa seção inicia-se com "It is evident that flexibility declines with age, with the maximum range of motion occurring in the mid- to late twenties for men e for women, respectively". Nesse aspecto, bastaria o senso comum para nos informar que a flexibilidade é muito maior em crianças do que em adultos jovens e que, portanto, não alcança seus níveis máximos ao redor dos 25 ou 30 anos de idade, conforme é afirmado no documento. Duas das três referências citadas para substanciar a informação apresentada provêm de dissertações de pós-graduação apresentadas, respectivamente, em 1955 e 1961, ambas incluindo somente dados de adultos. Na realidade, vale destacar o fato de que, das 248 referências listadas no documento, apenas uma pequena minoria possui mais do que 20 anos, incluindo as mencionadas acima. Seria provavelmente muito mais apropriado refrasear a sentença, afirmando que a flexibilidade nitidamente diminui com a idade, tanto nos homens como nas mulheres.

\section{4) ACSM Position Stand: The Recommended Quantity and Quality of Exercise for Developing and Maintaining Cardiorespiratory and Muscular Fitness, and Flexibility Healthy Adults (Med Sci Sports Exerc 1998;30:975-991)}

P. 983: No último parágrafo da primeira coluna dessa página do documento existe uma sentença que informa "... a minimum of 1 set of 8-12 RM or to near fatigue should be completed by most participants; however, for older and more frail persons (approximately 50-60 yr of age and above), 10-15 repetitions may be more appropriate". Em adendo, se examinamos a tabela 1 (p. 978), o conceito de intensidade relativa para exercícios de sobrecarga muscular é baseado em 8-12 repetições para os adultos e 10-15 repetições para os idosos na mesma percentagem da contração voluntária máxima. Se a intenção é proteger os indivíduos mais velhos de um esforço desnecessário, tanto a sentença e a tabela tal como são atualmente apresentadas podem ser confusas e de difícil interpretação. Seria provavelmente mais apropriado explicitar que os indivíduos idosos devem realizar exercícios de sobrecarga muscular com cargas mais baixas e com menores velocidades, ao invés de propor um aumento no número de repetições por série no mesmo percentual da força voluntária máxima.

A tabela 1 também apresenta vários outros erros óbvios. A tentativa de classificar a intensidade do esforço em termos percentuais de uma dada variável é interessante, mas provavelmente incorreta na maioria das vezes. Pegando como exemplo um homem idoso com uma freqüência cardíaca máxima de $160 \mathrm{bpm}$, dificilmente pode ser imaginado que ele possa exercitar-se a $35 \%$ de sua freqüência cardíaca máxima, isto é $56 \mathrm{bpm}$, por menos intenso e leve que seja a atividade física realizada, já que a maioria desses indivíduos possui freqüência cardíaca de repouso na posição ortostática superior a esse valor. Em adendo, qual é o significado de propor como um exercício muito leve aquele cuja intensidade absoluta não excede 1 MET em um homem muito idoso, já que, por definição, 1 MET representa o consumo de oxigênio basal e, portanto, não se pode consumir menos oxigênio do que isso, especialmente durante um exercício físico. Talvez um equívoco ainda mais evidente é feito na afirmação "mean values for women are approximately 1-2 METs lower than those for men", o que, em alguns casos, resultaria em consumos de oxigênio negativos para mulheres idosas realizando exercícios leves ou muito leves. Se alguma correção deve ser feita para comparar a intensidade de exercícios em homens e mulheres, o que é questionável em princípio, ela deve ser realizada em termos percentuais, isto é, relativos, e não em termos absolu- 
tos, ou seja, em METs. Por último, mas não menos importante, deverá destacar-se o efeito multiplicador desses erros, pois eles são também reproduzidos em outro documento da AHA/ ACSM (2).

Concluindo, é nossa intenção, de forma bastante simples, desmistificar os documentos institucionais como bíblias profissionais ou legais. É certamente verdadeiro que eles são nor- malmente muito bem redigidos e representam documentos relevantes, mas feitos por seres humanos normais e, portanto, falíveis, deverão ser alvo de leitura crítica e estudados cuidadosamente, antes que suas recomendações possam ser aceitas, adotadas ou implementadas. Estas observações podem ainda ser úteis para todos aqueles que vierem a participar da redação de documentos institucionais. 